\title{
Biophysical parameters in a wheat production region in southern Brazil
}

\author{
Janice F. Leivas ${ }^{*}$, Antonio Heriberto de C. Teixeira ${ }^{a}$, Ricardo G. Andrade ${ }^{a}$, Daniel de C. Victoria ${ }^{a}$, \\ Edson L. Bolfe ${ }^{\mathrm{a}}$, Caroline R. Cruz \\ ${ }^{a}$ Embrapa Monitoramento por Satélite, Campinas, São Paulo, Brazil \\ ${ }^{b}$ Pontifical Catholic University, Campinas, São Paulo, Brazil
}

\begin{abstract}
Wheat (Triticum aestivum) is the second most produced cereal in the world, and has major importance in the global agricultural economy. Brazil is a large producer of wheat, especially the Rio Grande do Sul state, located in the south of the country. The purpose of this study was to analyze the estimation of biophysical parameters - evapotranspiration (ET), biomass (BIO) and water productivity (WP) - from satellite images of the municipalities with large areas planted with wheat in Rio Grande do Sul (RS). The evapotranspiration rate was obtained using the SAFER Model (Simple Algorithm for Retrieving Evapotranspiration) on MODIS (Moderate Resolution Imaging Spectroradiometer) images taken in the agricultural year 2012. In order to obtain biomass and water productivity rates we applied the Monteith model and the ratio between BIO and ET. In the beginning of the cycle (the planting period) we observed low values for ET, BIO and WP. During the development period, we observed an increase in the values of the parameters and decline at the end of the cycle, for the period of the wheat harvest. The SAFER model proved effective for estimating the biophysical parameters evapotranspiration, biomass production and water productivity in areas planted with wheat in Brazilian Southern. The methodology can be used for monitoring the crops' water conditions and biomass using satellite images, assisting in estimates of productivity and crop yield. The results may assist the understanding of biophysical properties of important agro-ecosystems, like wheat crop, and are important to improve the rational use of water resources.
\end{abstract}

Keywords: evapotranspiration, biomass, water production, wheat.

\section{INTRODUCTION}

Wheat (Triticum aestivum) is the second most produced cereal in the world, and has major importance in the global agricultural economy. Brazil is a large producer of wheat, especially the Rio Grande do Sul state, located in the south of the country. This winter grass is highly susceptible to weather and climate conditions. It is grown under an intercropping system with soybean and maize, during summer, and depends on the annual variations in amounts produced by the previous crop. The most traditional growing area, the Southern Region, does not have a dry season, and the excessive humidity is favorable to the occurrence of diseases, late frosts (in the spring, coinciding with the silking of wheat) and hail, which are the main climate-related limitations [1]. Brazilian wheat-adaptation regions have already been determined, and are described as homogeneous regions and grouped by municipalities. In Brazil, wheat is grown in the South, Southeast and Midwest regions [2].The national wheat production is not enough for domestic consumption, and there is a deficit of 5.8 million tons, i.e. there is a strong dependence on foreign markets. The Ministry of Agriculture estimates an annual increase of $1.31 \%$ in wheat production by 2020 , and a consequent reduction in imports. Researches indicate that it is essential to discuss the progress made in improving the agronomic performance of wheat to increase yield and improve efficiency in the use of environmental resources.

Remote sensing using satellites is an efficient tool for these estimates, providing spatiotemporal information, location and stage of different agro-ecosystems [3]. The high correlation between the spectral bands and biophysical parameters

*janice.leivas@embrapa.br; phone 005519 3211-6200; Fax: 0055 19 3211-6222; cnpm.embrapa.br

Remote Sensing for Agriculture, Ecosystems, and Hydrology XVI, edited

by Christopher M. U. Neale, Antonino Maltese, Proc. of SPIE Vol. 9239, 923924

(C) 2014 SPIE · CCC code: 0277-786X/14/\$18 · doi: 10.1117/12.2067477 
enables mapping and quantifying BIO on a large scale [4]. Landsat satellite images have been used for biomass estimates in the São Francisco [3] and Amazon [5] basins.

The SAFER (Simple Algorithm for Evapotranspiration Retrieving) algorithm for retrieving ET has been developed and validated using field data and Landsat images applied to irrigated crops and natural vegetation in the Brazilian semiarid conditions [6-7]. One of the SAFER model's advantages is that data from both automatic and conventional agrometeorological stations can be used, which enables a wider temporal evaluation of BIO and ET. A second biophysical model was also developed for the estimation of the surface resistance to water fluxes $\left(\mathrm{r}_{\mathrm{s}}\right)$ on a large scale, which established threshold values which are useful for classifying the vegetation into irrigated crops and natural vegetation [8].

Faced with the variability in yield and economic importance of cereal crops, the purpose of this study is to analyze estimates of biophysical parameters of wheat crops for development and productivity monitoring using satellite images and meteorological data, along with the SAFER algorithm [7].

\section{MATERIAL AND METHODS}

The study area consists of wheat production municipalities in the state of Rio Grande do Sul, Southern Brazil (Figure 1). For this study, we used daily data from agrometeorological stations provided by Brazilian National Institute of Meteorology (INMET - Instituto Nacional de Meteorologia), and processed MODIS (Moderate Resolution Imaging Spectroradiometer) data, product MOD13Q1, reflectance bands $1(\alpha 1)$ and $2(\alpha 2)$, with a spatial resolution of $250 \mathrm{~m}$ and a temporal resolution of 16 days. The satellite images selected correspond to the wheat agricultural calendar in the region, between June (planting) and November (harvest), year 2012, totaling 11 images. The SAFER[7] (Simple Algorithm for Retrieving Evapotranspiration) model was applied to obtain evapotranspiration and biomass rates. To obtain the water productivity rate we applied the Monteith model and the ratio between BIO and ET. The results have been extracted for the Rio Grande do Sul state land-use mask, available by Brazilian Institute of Geography and Statistics (IBGE).

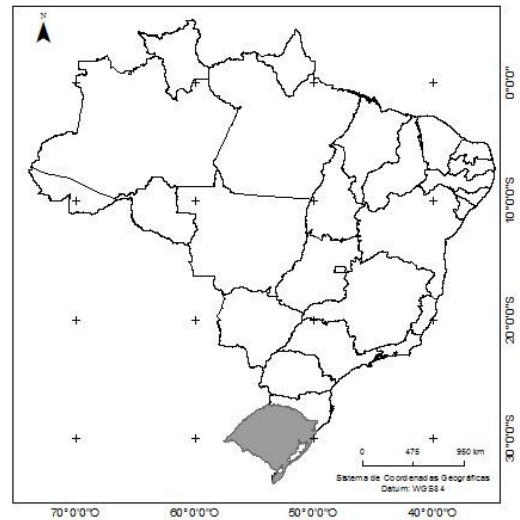

Figure 1. Location of the Rio Grande do Sul state, Brazilian Southern region (shaded area).

For the surface albedo $\left(\alpha_{0}\right)$ calculations the reflectance values from the bands 1 and 2, extracted from the MODIS product MOD13Q1, with a time scale of 16 days were used, insuring a spatial resolution of $250 \mathrm{~m}$ for all water productivity parameters [9]:

$$
\alpha_{0}=\mathrm{a}+\mathrm{b} \alpha_{1}+\mathrm{c} \alpha_{2}
$$

where $\alpha_{1}$ and $\alpha_{2}$ are the reflectance values for the bands 1 and 2 from MODIS satellite measurements, and a, b, and $\mathrm{c}$ are regression coefficients obtained comparing these measurements with field data [10,11], thus including the atmospheric effects through the radiation path. Their values found for the Brazilian semiarid conditions were, respectively, $0.08,0.41$ and 0.14 .

For the surface temperature ( $\left.\mathrm{T}_{0}\right)$, the thermal radiation balance equation was applied [12]: 


$$
\mathrm{T}_{\mathrm{S}}=\sqrt[4]{\frac{\mathrm{R}_{\mathrm{G}}-\alpha_{0} \mathrm{R}_{\mathrm{G}}+\varepsilon_{\mathrm{A}} \sigma \mathrm{T}_{\mathrm{a}}^{4}-\mathrm{R}_{\mathrm{n}}}{\varepsilon_{\mathrm{S}} \sigma}}
$$

where $R_{G}$ and $T_{a}$ are respectively the daily values of the incident solar radiation and mean air temperature at the agrometeorological stations, $\mathrm{R}_{\mathrm{n}}$ is the daily net radiation, $\varepsilon \mathrm{A}$ and $\varepsilon \mathrm{s}$ are respectively the atmospheric and surface emissivities, and $\sigma$ is the Stefan-Boltzmann constant (5.67 x 10-8 W m-2 K-4).

$\varepsilon s$ and $\varepsilon$ A were calculated as follows [13-14] :

$$
\begin{gathered}
\varepsilon_{\mathrm{S}}=\mathrm{a}_{\mathrm{S}} \ln \mathrm{NDVI}+\mathrm{b}_{\mathrm{S}} \\
\varepsilon_{\mathrm{A}}=\mathrm{a}_{\mathrm{A}}+\left(\ln \tau_{\mathrm{S}}\right)^{\mathrm{b}_{\mathrm{A}}}
\end{gathered}
$$

where $\tau_{\mathrm{s}}$ is the short-wave transmissivity calculated as the ratio of $\mathrm{R}_{\mathrm{G}}$ to the incident solar radiation at the top of the atmosphere, and as, bs, aA and $\mathrm{b}_{\mathrm{A}}$ are regression coefficients taken as $0.06,1.00,0.94$ and 0.10 according to [14].

Daily $\mathrm{R}_{\mathrm{n}}$ can be described by the 24-hour values of net shortwave radiation, with a correction term for net longwave radiation for the same time-scale [14]:

$$
\mathrm{R}_{\mathrm{n}}=\left(1-\alpha_{0}\right) \mathrm{R}_{\mathrm{G}}-\mathrm{a}_{1} \tau_{\mathrm{sw}}
$$

where al is the regression coefficient of the relationship between net long wave radiation and $\tau_{\mathrm{sw}}$ on a daily scale. Because of the thermal influence on longwave radiation via the Stephan Boltzmann equation, a previous study investigated whether the variations of the al coefficient from Eq. 6 could be explained by variations in 24 hours $\mathrm{Ta}_{\mathrm{a}}$ [14]:

$$
\mathrm{a}_{1}=\mathrm{dT}_{\mathrm{a}}-\mathrm{e}
$$

where $\mathrm{d}$ and e are regression coefficients found to be 6.99 and 39.93 respectively for the Brazilian Northeast conditions. The SAFER algorithm is used to model the instantaneous values of the ratio ET/ETo, which is then multiplied by ETo from the weather stations to estimate the daily ET large-scale values:

$$
\frac{\mathrm{ET}}{\mathrm{ET}_{0}}=\left\{\exp \left[\mathrm{f}+\mathrm{g}\left(\frac{\mathrm{T}_{0}}{\alpha_{0} \mathrm{NDVI}}\right)\right]\right\} \frac{\mathrm{ET}_{\text {ano }}}{5}
$$

where ETo is the map of reference evapotranspiration from the 34 weather stations (Figure 1) calculated by the PenmanMonteith method [33] and $f$ and $g$ are the original regressions coefficients, 1.9 and - 0.008 [14], respectively. The correction factor $\left(\mathrm{ET} \mathrm{ano}_{\mathrm{ano}} / 5\right)$ was applied, where ET0 year is the annual grids of reference evapotranspiration for Rio Grande do Sul state in 2012, and $5 \mathrm{~mm}$ is the value of ET0year for the period of modelling in the original semi-arid region. The evaporative fraction $(\mathrm{E} f)$ is included to take into account the soil moisture effects, and is defined as the latent heat flux $(\lambda \mathrm{E})$ divided by the available energy, which in turn is the difference between $\mathrm{R}_{\mathrm{n}}$ and soil heat flux $(\mathrm{G})$ :

$$
\mathrm{E}_{\mathrm{f}}=\frac{\lambda \mathrm{E}}{\mathrm{R}_{\mathrm{n}}-\mathrm{G}}
$$

where $\lambda \mathrm{E}$ is obtained by transforming $\mathrm{ET}$ into energy units, with all energy terms considered in $\mathrm{MJ} \mathrm{m}-2$ day-1 in the

SAFER algorithm.

For the daily $\mathrm{G}$ values, the equation derived by [13] was used:

$$
\frac{\mathrm{G}}{\mathrm{R}_{\mathrm{n}}}=\mathrm{a}_{\mathrm{G}} \exp \left(\mathrm{b}_{\mathrm{G}} \alpha_{0}\right)
$$

where $\mathrm{ag}_{\mathrm{G}}$ and $\mathrm{b}_{\mathrm{G}}$ are regression coefficients found to be 3.98 and -25.47 respectively.

$R_{G}$ daily values were used to estimate the large scale Photosynthetically Active Radiation (PAR) for the daily time-scale:

$$
\mathrm{PAR}=\mathrm{hR}_{\mathrm{G}}
$$

where $\mathrm{h}=0.44$ is the constant of the regression equation found under the Brazilian conditions that reflects the portion of RG that can be used by leaf chlorophyll for photosynthesis [15].

The values of Absorbed Photosynthetically Active Radiation (APAR) can be approximated directly from PAR:

$$
\mathrm{APAR}=\mathrm{f}_{\mathrm{PAR}} \mathrm{PAR}
$$


The factor fPAR is estimated from the NDVI values $[16,17]$ :

$$
\mathrm{f}_{\mathrm{PAR}}=\mathrm{iNDVI}+\mathrm{j}
$$

The coefficients $i$ and $j$ of 1.257 and -0.161 , respectively, reported for a mixture of arable crop types [17] were considered and the BIO is quantified as:

$$
\mathrm{BIO}=\varepsilon_{\max } \mathrm{E}_{\mathrm{f}} \mathrm{APAR} 0.864
$$

where $\varepsilon$ max is the maximum light use efficiency, which depends on whether the vegetation is $\mathrm{c} 3 \mathrm{or} \mathrm{c} 4$ species, and 0.864 is a unit conversion factor $[15,16]$.

In the current research, the water productivity (WP) assessments are done in terms of ET [15]:

$$
\mathrm{WP}=\frac{\mathrm{BIO}}{\mathrm{ET}}
$$

Subsequently, the ET average values have been extracted according to the cropping mask of Rio Grande do Sul state, the scale of which is $1: 100.000$.

\section{RESULTS AND DISCUSSION}

Figures 2, 3 and 4 show the spatial distribution of evapotranspiration (ET), biomass (BIO) and water productivity (WP) daily values for wheat production municipalities in the Rio Grande do Sul state, on June 26, August 13, September 30, and November 1, 2012. These dates have been selected because of the developmental stage of the wheat cycle.

Based on the agricultural areas of southern Brazil occupied by wheat fields at the beginning of the cycle, the average ET values obtained were $1.17 \pm 0.46 \mathrm{~mm} \mathrm{~d}^{-1}$. BIO presented average values of $34.28 \pm 21.03 \mathrm{~kg} \mathrm{~m}^{-2}$ and $2.64 \pm 0.77 \mathrm{WP} \mathrm{kg}$ $\mathrm{m}^{-3}$.

Along the development of the wheat, the biophysical parameters' variability may be observed over the cycle. The biophysical parameters were higher at mid-cycle, which is related to the crop's maturation period, therefore there is a higher loss of water to the atmosphere in the form of evapotranspiration, a higher biomass production and a higher water productivity, as it can be seen in the ET, BIO and PA values, which correspond to $2.59 \pm 0.68 \mathrm{~mm} . \mathrm{d}^{-1}, 100.46 \pm 39.05 \mathrm{~kg}$ $\mathrm{m}^{-2}$ and $3.72 \pm 0.63 \mathrm{~kg} \mathrm{~m}^{-3}$, respectively.

At the end of the crop cycle and harvest time, there was a reduction in the biophysical parameters, with an ET average around $1.27 \pm 0.89 \mathrm{~mm} . \mathrm{d}^{-1}$, a BIO average around $33.04 \pm 32.03 \mathrm{~kg} \mathrm{~m}^{-2}$, and a WP $2.07 \pm 0.81 \mathrm{~kg} \mathrm{~m}^{-3}$, respectively.

The values have been extracted according to the cropping mask of the Rio Grande do Sul state, the scale of which is $1: 100.000$.

The average daily ET of wheat production areas at the planting period (June 26, 2012) was $1.99 \pm 0.61 \mathrm{~mm} . \mathrm{d}^{-1}$. At the development stage of wheat (August 13), the average ET was $2.60 \pm 0.57 \mathrm{~mm} . \mathrm{d}^{-1}$. At harvest (September 30 ), we

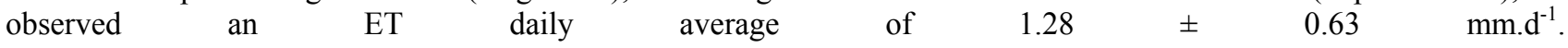
The average BIO wheat production municipalities in Southern Brazil ranged around $72.36 \pm 34.55$ for the planting period, with increased values of biomass in the crop-development period (August 13) of around 102.79 $\pm 34.86 \mathrm{~mm} . \mathrm{d}^{-1}$. During the harvest period, the average biomass was around $32.72 \pm 23.44 \mathrm{~mm} \cdot \mathrm{d}^{-1}$. The average WP ranged around $3.41 \pm 0.78$ (June). In August 13, the WP was around $3.83 \pm 0.57 \mathrm{~mm} . \mathrm{d}^{-1}$, and at the cycle's end, the WP was around $2.22 \pm 0.69 \mathrm{~mm} \cdot \mathrm{d}^{-1}$.

The low evapotranspiration values at the beginning and the end of the cycle are due to fact that wheat is a winter crop, and is in agreement with the time when incident radiation fluxes, and consequently the air temperature, are the lowest in the year. Thus, there is high soil moisture, but not enough to promote high rates of evapotranspiration. This result is in agreement with the normal climatological provided by the Brazilian National Institute of Meteorology (INMET), which, for the month of August, is equal to $43 \mathrm{~mm} . \mathrm{month}^{-1}$, and corresponds to an average of $1.38 \mathrm{~mm} . \mathrm{d}^{-1}$. As we mentioned previously, the highest average evapotranspiration value was $1.41 \mathrm{~mm} \cdot \mathrm{d}^{-1}$ and occurred in August. The results corroborate with others studies at same region [18] when applying the SEBAL algorithm over the same period of the year in the state of Paraná, Southern Brazil.

Zwart et al. (2010) [19] have applied the method for mapping water productivity of wheat around the world and obtained a range of 0.52 to $1.42 \mathrm{~kg} \cdot \mathrm{m}^{-3}$ [20]. The SEBAL algorithm was used to quantify the spatial variation of crop yield, evapotranspiration (ET) and water productivity (WP) using NOAA/AVHRR and Landsat satellite images. The results were validated using irrigated wheat in Mexico. The water productivity (WP) average in the Yaqui Valley, Mexico, was $1.37 \mathrm{~kg} \cdot \mathrm{m}^{-3}$, and can be considered high when compared to other irrigation systems around the world where the same 
methodology was applied. The highest average WP was found in the Nile Delta of Egypt $\left(1.52 \mathrm{~kg} . \mathrm{m}^{-3}\right)$, Kings County (CA), USA $\left(1.44 \mathrm{~kg} . \mathrm{m}^{-3}\right)$ and Oldambt, Netherlands $\left(1.39 \mathrm{~kg} \cdot \mathrm{m}^{-3}\right)$.
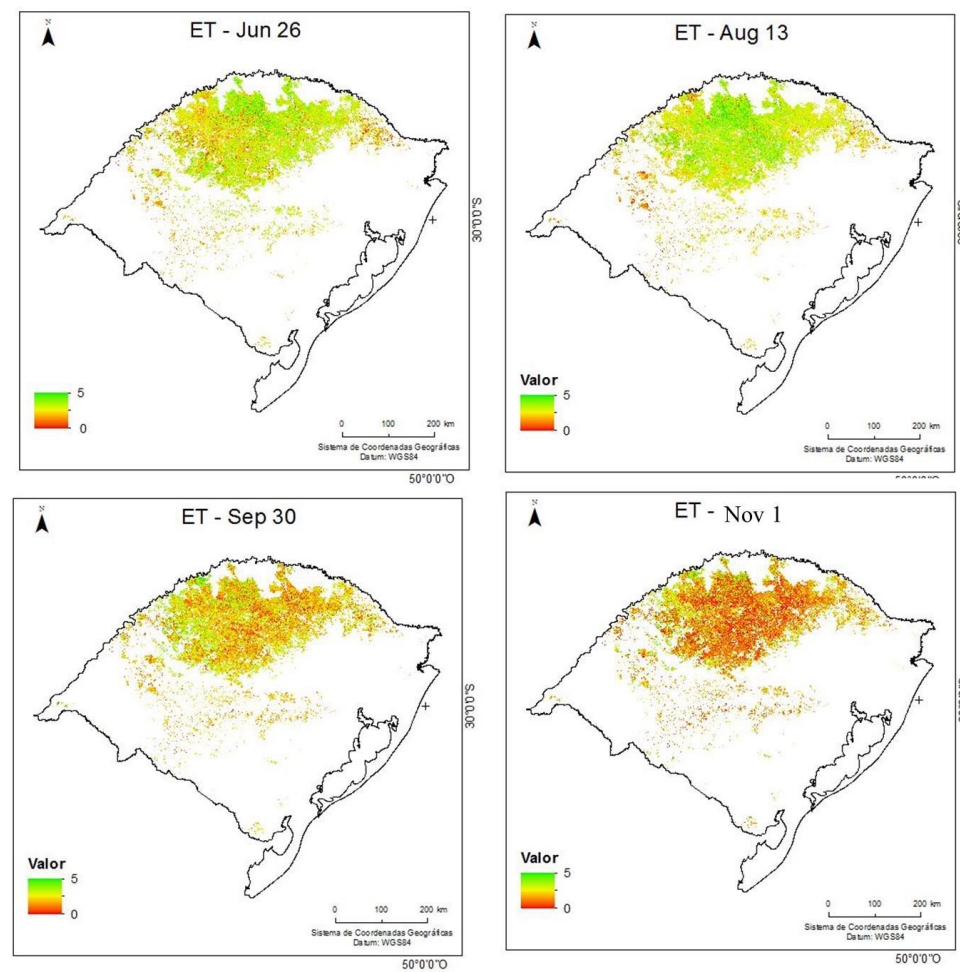

Figure 2. Spatial distribution of daily evapotranspiration (ET) during the agricultural year (2012) for wheat, in Rio Grande do Sul, Brazilian Southern region.
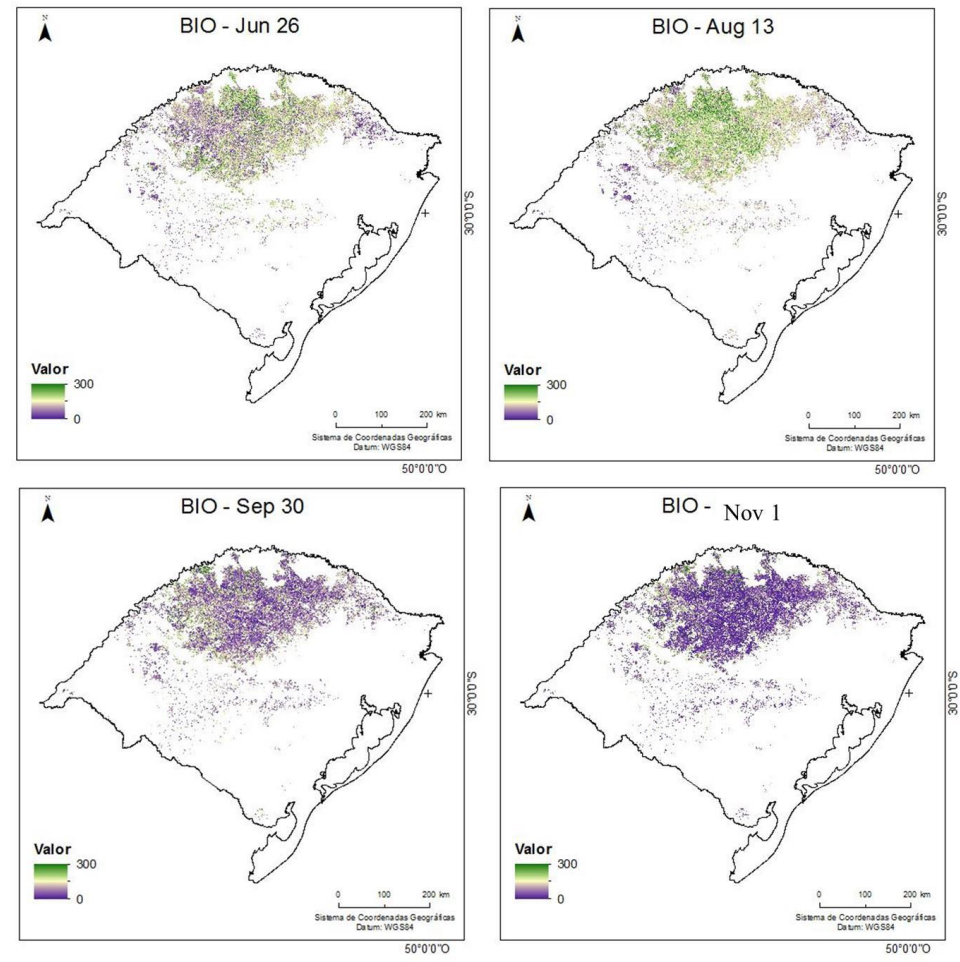

Figure 3. Spatial distribution of biomass production (BIO) during the agricultural year (2012) for wheat, in Rio Grande do Sul, Brazilian Southern region. 

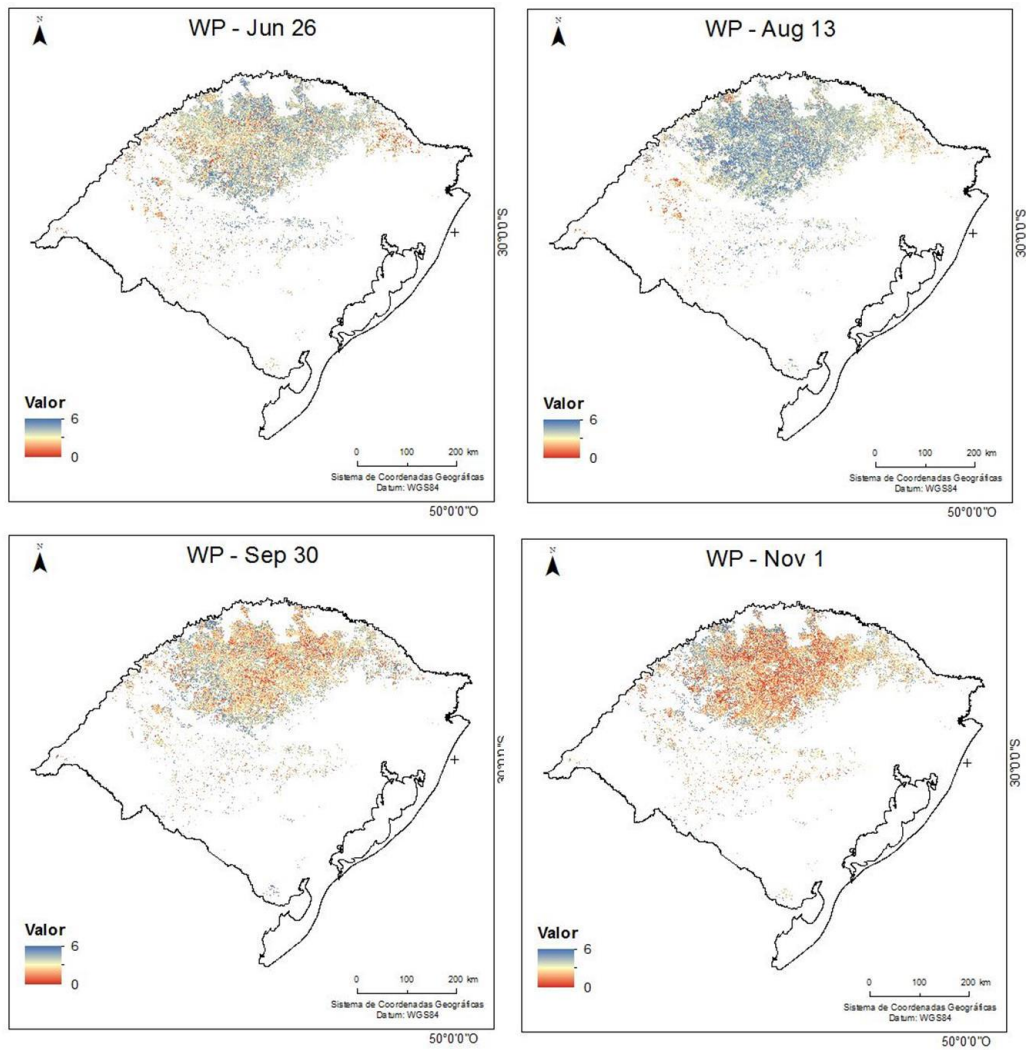

Figure 4. Spatial distribution of water production (WP) during the agricultural year (2012) for wheat, in Rio Grande do Sul, Brazilian Southern region.

Evapotranspiration, biomass and water productivity present higher values in the middle of the crop's development cycle, therefore there is a higher loss of water to the atmosphere in the form of evapotranspiration, and a higher biomass and water productivity rate on August 13, which are related to the crop development period. Evapotranspiration estimation methods generally enable obtaining data on a local scale. However, regions with heterogeneous surfaces with different types of soil and vegetation present quite different evaporation rates, which cannot be perceived in traditional estimation methods. Remote sensing allows the estimation of evapotranspiration over large areas, as a function of biophysical characteristics obtained at each pixel. Another major advantage of the use of satellite imagery in estimating evapotranspiration on a regional scale is that the amount of water consumed in the evapotranspiration process can be detected without the need for quantification of other hydrological parameters, such as soil moisture.

\section{CONCLUSIONS}

The SAFER model proved effective for estimating the biophysical parameters evapotranspiration, biomass production and water productivity in areas planted with wheat in Rio Grande do Sul. Therefore, the method may be used for the monitoring of crop water conditions and biomass using satellite images, thus assisting in estimates of productivity and crop yield. The results may assist the understanding of biophysical properties of important agro-ecosystems, like wheat crop, and are important to improve the rational use of water resources.

\section{REFERENCES}

[1] Cunha, G. R. da, Pires, J. L. F.; Dalmago, G. A.; Caierão, E., Paisnato, A. [Agrometeorologia dos cultivos: o fator meteorológico na produção agrícola], INMET, Brasília, 281-293 (2009).

[2] Cunha, G. R. da, Haas, J. C., Maluf, J. R. T., Caramori, P. H., Assad, E. D., Braga, H. J., Zullo Jr, J., Lazzarotto, C., 
Gonçalves, S., Wrege, M., Brunetta, D., Dotto, S. R., Pinto, H. S., Brunini, O., Thomé, V. M. R., Zampieri, S. L., Pasinato, A., Pimentel, M. B. M., Pandolfo, C. "Zoneamento agrícola e época de semeadura para trigo no Brasil," Revista Brasileira de Agrometeorologia 9(3), 400-414 (2001).

[3]Teixeira, A.H. de C. Water productivity assessments from field to large scale: a case study in the Brazilian semi-arid region], LAP Lambert Academic Publishing: Saarbrücken, Germany, 226p. (2009).

[4]Ahamed, T., Tian, L., Zhang, Y., Ting, K. C. "A review of remote sensing methods for biomass feedstock production," Biomass Energ. 35, 2455-2469, (2011).

[5] Lu, D. "Aboveground biomass estimation using Landsat TM data in the Brazilian Amazon basin," Int. J. Remote Sens. 26, 2509-2525, (2005).

[6] Teixeira, A. H. de C., Bastiaanssen, W. G. M., Ahmad, M. D., Bos, M. G. "Analysis of energy fluxes and vegetationatmosphere parameters in irrigated and natural ecosystems of semi-arid Brazil,".J. Hydrol.362, 110-127 (2008b).

[7] Teixeira, A. H. de C. Modelling evapotranspiration by remote sensing parameters and agro-meteorological stations. In: Remote Sensing and Hydrology (ed. by C. M. U. Neale \& M. H. Cosh), 154-157. IAHS Publ. 352. IAHS Press, Wallingford, UK (2012).

[8] Teixeira, A. H. de C. Determination of surface resistance to evapotranspiration by remote sensing parameters in the semi-arid region of Brazil for land-use change analyses. In: Remote Sensing and Hydrology (ed. by C. M. U. Neale \& M. H. Cosh), 167-170. IAHS Publ. 352. IAHS Press, Wallingford, UK (2012).

[9] Valiente, J. A., Nunez, M., Lopez-Baeza, E., Moreno, J. F. "Narrow-band to broad-band conversion for Meteosat visible channel and broad-band albedo using both AVHRR-1 and -2 channels". Int. J. Rem. Sens. 16, 1147-1166 (1995).

[10] Teixeira, A.H. de C., Scherer-Warren, M., Hernandez, F.B.T., Andrade, R.G., Leivas, J.F. "Large-Scale Water Productivity Assessments with MODIS Images in a Changing Semi-Arid Environment: A Brazilian Case Study," Rem. Sens. 55783-5804 (2013).

[11] Teixeira, A.H. de C., Hernandez, F.B.T., Lopes, H.L., Scherer-Warren, M., Bassoi, L.H. A Comparative Study of Techniques for Modeling the Spatiotemporal Distribution of Heat and Moisture Fluxes in Different Agroecosystems in Brazil. In: George G. Petropoulos. (Org.). Remote Sensing of Energy Fluxes and Soil Moisture Content. 1ed.Boca Raton, Florida: CRC Group, Taylor and Francis, 169-191 (2014a).

[12] Teixeira, A.H. de C., Hernandez, F.B.T., Andrade, R.G., Leivas, J.F., Victoria, D. de C., Bolfe, E.L. Irrigation performance assessments for corn crop with Landsat images in the São Paulo state, Brazil. Proc. INOVAGRI 739-748 (2014b).

[13] Teixeira, A. H. de C. "Determining regional actual evapotranspiration of irrigated and natural vegetation in the São Francisco river basin (Brazil) using remote sensing an Penman-Monteith equation,” Rem. Sens., 2, 1287-1319 (2010).

[14] Teixeira, A.H. de C., Hernandez, F.B.T., Lopes, H.L., Scherer-Warren, M., Bassoi, L.H. A Comparative Study of Techniques for Modeling the Spatiotemporal Distribution of Heat and Moisture Fluxes in Different Agroecosystems in Brazil. In: George G. Petropoulos. (Org.). Remote Sensing of Energy Fluxes and Soil Moisture Content. 1ed.Boca Raton, Florida: CRC Group, Taylor and Francis, 169-191 (2014a).

[15] Teixeira, A.H. de C. Water productivity assessments from field to large scale: a case study in the Brazilian semi-arid region; LAP Lambert Academic Publishing: Saarbrücken, Germany, 226p. (2009).

[16]Teixeira, A. H. de C., Bastiaanssen, W. G. M., Ahmad, M-ud-D, Bos, M. G. "Reviewing SEBAL input parameters for assessing evapotranspiration and water productivity for the Low-Middle São Francisco River basin, Brazil Part B: Application to the large scale," Agric. For. Meteorol. 149, 477-490 (2009). 
[17] Bastiaanssen, W.G.M., Ali, S., 2003. "A new crop yield forecasting model based on satellite measurements applied across the Indus Basin, Pakistan," Agric. Ecosyst. Environ. 94 (3), 32-340 (2003).

[18] Paiva, C. M., Liu, W. T. H., França, G. B. "Determinação da evapotranspiração da cultura de trigo pelo método do balanço de energia - Razão de Bowen - para Londrina (PR),” Proc. CBMet, 159-164 (2012).

[19] Zwart, S.J., Bastiaanssen, W.G.M., Fraiture de F., Molden, D.J. “WATPRO: A remote sensing based model for mapping water productivity of wheat,” Agric. Water Manage. 97, 1628-1636 (2010).

[20] Zwart, S.J., Bastiaanssen, W.G.M. "SEBAL for detecting spatial variation of water productivity and scope for improvement in eight irrigated systems," Agric. Water Manage. 89, 287-296 (2007). 